\title{
EFFECT OF STRESS-STRAIN STATE DURING HELICAL ROLLING ON METAL AND ALLOY STRUCTURE AND DUCTILITY
}

\author{
A. A. Bogatov ${ }^{1}$ and E. I. Panov ${ }^{2}$ \\ UDC 621.77.01:669.715:669.14
}

A working hypothesis is proposed for the mechanism of the effect of deformation regimes on granular structure and phase fineness governing an increase in ductility for silumins and low-alloy steels. In particular, an alternating nature of deformation during helical rolling (HR) provides a reduction in grain size by a factor of 5-6 compared with longitudinal rolling. For hypereutectic silumins with HR it is possible to obtain a polygonized subgranular structure, to increase $\alpha$-solid solution grain and silicon crystal fineness, giving them a globular shape, and thereby provide a capacity for treatment under pressure. An important role in increasing deformation capacity of silumins is played by the new technology of melt modifying treatment and optimum temperature-rate deformation regimes.

Keywords: hypereutectic silumins, deformation, strength, ductility, alternating deformation, low-alloy steels, cast iron, melt modifying treatment, polygonized subgranular structure.

Hypereutectic silumins containing more than $17 \%$ silicon exhibit low density $\left(\rho=26-27 \mathrm{~g} / \mathrm{cm}^{3}\right)$, satisfactory strength ( $\sigma_{\mathrm{u}}=190-320 \mathrm{MPa} ; \sigma_{0.2}=155-260 \mathrm{MPa}, E=75-80 \mathrm{GPa} ; \sigma_{-1}=90-130 \mathrm{MPa}$ ). In a cold condition, relative elongation $\delta$ is not more than $1 \%$, and relative reduction of area $\psi$ is up to $4 \%$. Strength properties of silumins are maintained to $T=-70^{\circ} \mathrm{C}$. Silumins have typically good production and user properties: high fluidity, low shrinkage during solidification; good weldability, high corrosion resistance, heat and wear resistance; low linear thermal expansion coefficient; nonmagnetic nature [1].

Technology for preparing high silicon master alloys, based on a carbothermal reduction method of cheap and widespread raw material (nepheline, alunite, kaolin, etc.) makes it possible to reduce silumin cost by 15-20\% compared with the currently used technology for synthesizing aluminum with silicon.

Hypereutectic silumins may be considered as natural composite materials, having a two-phase structure consisting of ductile eutectic matrix and brittle primary silicon crystals with a size of not more than $150 \mu \mathrm{m}$, and also crystals of iron, titanium, and zirconium aluminides (intermetallic phases). An increase in phase fineness, playing the role of a filler, promotes an increase in both strength and ductility. Silumin alloys after processing $\mathrm{SiC}$ and $\mathrm{Al}_{2} \mathrm{O}_{3}$ powders have high strength $\left(\sigma_{\mathrm{u}}=\right.$ $=650-700 \mathrm{MPa}$ ).

Objects of high-silicon hypereutectic silumins because of their low ductility are prepared by molding and centrifugal casting (pipes) and liquid stamping, for example, production of internal combustion engine pistons. Further expansion of the range of these applications is connected with the solution of the problem of increasing alloy workability, development, and introduction of forming technology.

\footnotetext{
${ }^{1}$ Yeltsin Ural Federal University (UrFU), Ekaterinburg, Russia; e-mail: omd@mtf.ustu.ru.

2 Tsvetmetobrabotka, Moscow, Russia.
}

Translated from Metallurg, No. 5, pp. 75-81, May, 2013. Original article submitted October 11, 2012. 

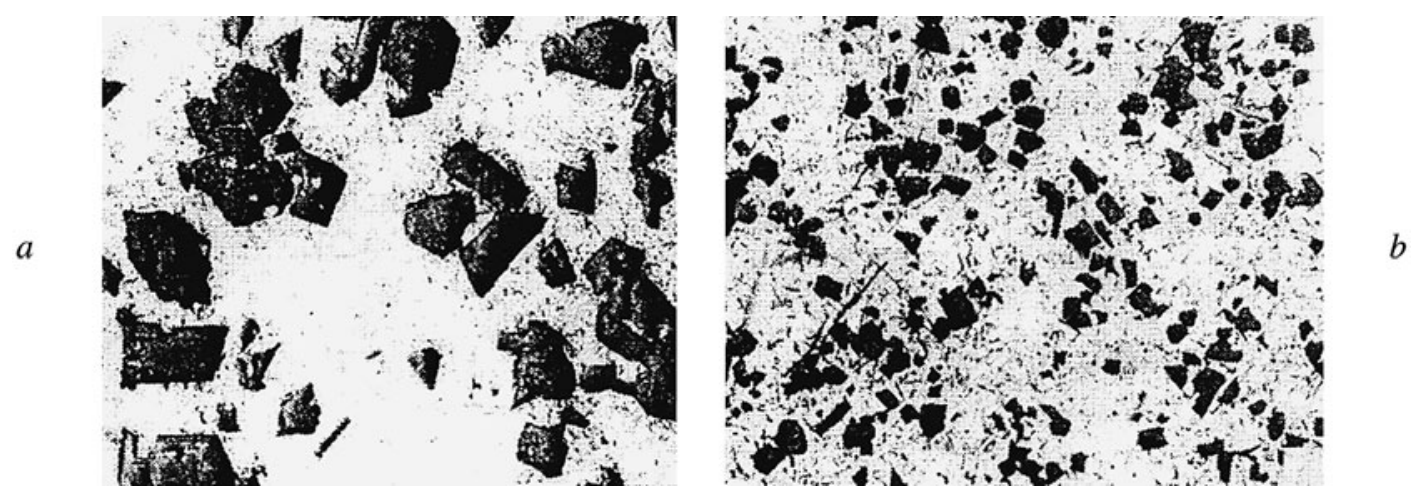

Fig. 1. CCB microstructure ( $\times 125)$ of hypereutectic silumins (17-20\% Si): $a$ ) before modification; $b)$ after combined modification, including melt UST.

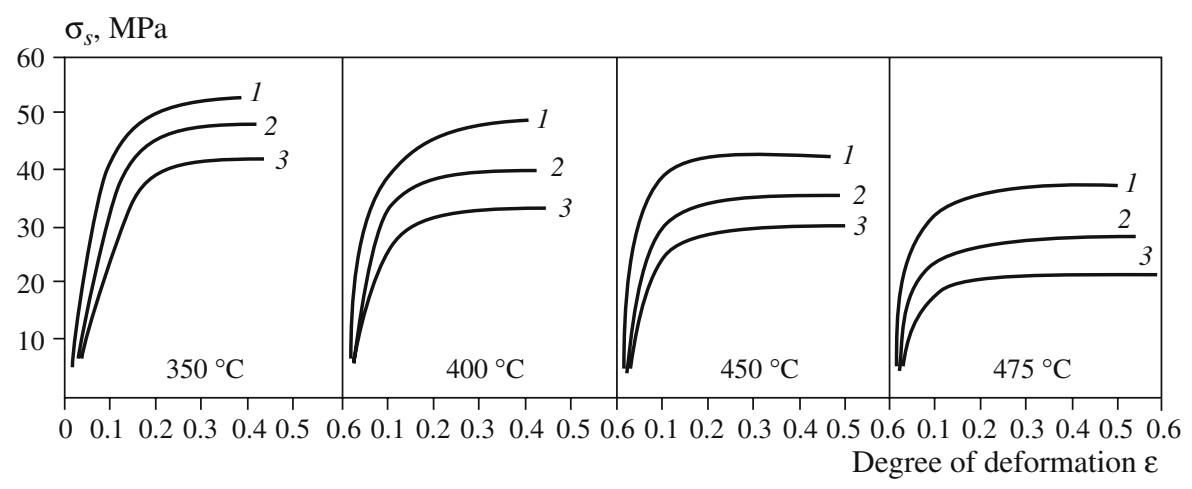

Fig. 2. Alloy 01390 deformation resistance curves with different deformation rates: 1) $2.5 \mathrm{sec}^{-1}$; 2) $0.5 \mathrm{sec}^{-1}$; 3) $0.1 \mathrm{sec}^{-1}$.

The presence in the structure of silumins of coarse silicon crystals with a size of 150-200 $\mu \mathrm{m}$ embrittles the alloy and makes it impossible to accomplish forming. Iron, titanium, and zirconium aluminides have the same effect.

In order to move to a classical scheme for manufacturing deformable semifinished products through an ingot manufacture by continuous casting (CCB), it is necessary to develop a technology for breaking up excess (primary) silicon crystals to sizes making it possible to increase the ductility of these billets. The most effective method for refining structural components of alloys is use of different modifiers.

Use of combined modification treatment of melt, including introduction of modifier (Al-Fe-P master alloy) and ultrasonic treatment (UST) of a stream of melt has made it possible not only to achieve refinement of silicon crystals to sizes of $60-70 \mu \mathrm{m}$, to increase billet ductility ( $\delta \geq 3 \%$ ), to overcome surface cracks in billets, but also to provide the possibility of subsequent deformation of these billets by hot pressing with preparation of pressed semifinished products [1].

The structure of a CCB prepared as result of combined modification is shown in Fig. 1.

Results of studying production properties, i.e., features of the change in alloy deformation resistance and ductility in relation to temperature and rate conditions of deformation, obtained during tensile testing of specimens selected from a CCB after combined modification with UST, are provided in Table 1. Analysis of test results (see Table 1) shows that the temperature range of $450-500^{\circ} \mathrm{C}$ is the optimum since strength properties $\left(\sigma_{u}\right.$ and $\left.\sigma_{0.2}\right)$ are at a minimum and ductility properties $(\delta$ and $\psi)$ have maximum values. 
TABLE 1. Effect of Deformation Rate and Test Temperature on Mechanical Properties with Tension for a Homogeneous Billet of Alloy 01390

\begin{tabular}{|c|c|c|c|c|c|c|c|c|c|c|c|c|}
\hline \multirow{2}{*}{ Temperature, ${ }^{\circ} \mathrm{C}$} & \multicolumn{3}{|c|}{$\sigma_{\mathrm{u}}, \mathrm{MPa}$} & \multicolumn{3}{|c|}{$\sigma_{0.2}, \mathrm{MPa}$} & \multicolumn{3}{|c|}{$\delta, \%$} & \multicolumn{3}{|c|}{$\psi, \%$} \\
\hline & 1 & 2 & 3 & 1 & 2 & 3 & 1 & 2 & 3 & 1 & 2 & 3 \\
\hline 20 & 185.5 & 174.5 & - & 143.5 & 152 & - & 4.6 & 3.2 & - & 7.3 & 4.1 & - \\
\hline 300 & 80.5 & 97 & 105.5 & 67 & 68 & 74 & 12.2 & 12.4 & 6 & 18.7 & 15 & 7.4 \\
\hline 350 & 48.5 & 74 & 81.5 & 36 & 51 & 56 & 16 & 19.6 & 17.2 & 29.6 & 26.1 & 20.1 \\
\hline 400 & 31 & 55.5 & 60.5 & 2.5 & 36 & 39.5 & 17.6 & 32.6 & 27.6 & 37.1 & 36 & 30.6 \\
\hline 450 & 21 & 43 & 47.5 & 18 & 31 & 35 & 28 & 32 & 22.4 & 47.5 & 34.3 & 27 \\
\hline 500 & 20 & 28.5 & 38 & - & 24.5 & 30.5 & 24.5 & 38.2 & 32.2 & 52 & 50.2 & 43.2 \\
\hline
\end{tabular}

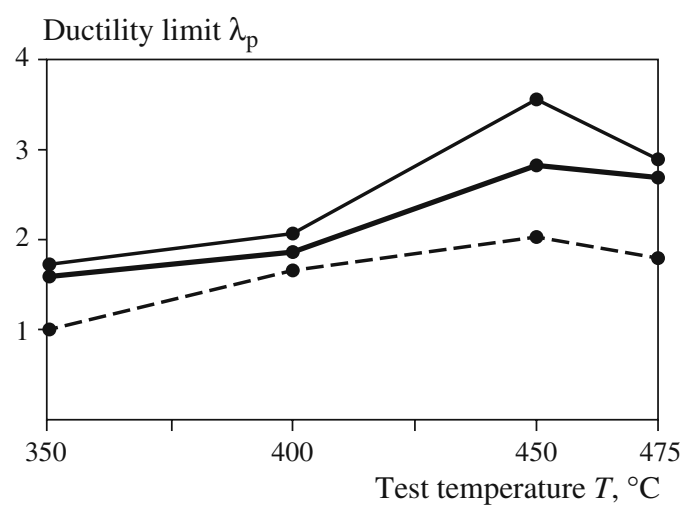

Fig. 3. Dependence of ductility limit for alloy 01390 on temperature-rate parameters during torsion testing: 1) deformation rate $\dot{\varepsilon}=0.1 \mathrm{sec}^{-1}$; 2) $0.5 \mathrm{sec}^{-1}$; 3) $2.5 \mathrm{sec}^{-1}$.

Results of tests in torsion for specimens are presented in Fig. 2. The nature of the strengthening curves with all temperature and rate conditions is the same. The intensity of alloy strengthening has the greatest value in the deformation range $\varepsilon=0-0.2$. With greater values of $\varepsilon$, deformation strengthening is almost absent.

The effect of deformation rate at all test temperatures $\left(350^{\circ} \mathrm{C}, 400^{\circ} \mathrm{C}, 450^{\circ} \mathrm{C}\right.$, and $\left.475^{\circ} \mathrm{C}\right)$ with any degree of deformation is marked, and $\Delta \sigma_{s}=10-18 \mathrm{MPa}$. ductility curves are presented in Fig. 3 in relation to test temperature and deformation rate [1]. The greatest ductility value $\left(\lambda_{\mathrm{p}}\right)$ for alloy is achieved at $450^{\circ} \mathrm{Cand}$ a deformation rate of $0.1 \mathrm{sec}^{-1}$.

With the optimum technology for combined alloy modification, including UST, the average silicon crystal size in a billet may be $20-40 \mu \mathrm{m}$, and a maximum in the range $50-70 \mu \mathrm{m}$. Silicon crystals and iron and titanium aluminides in eutectic have the shape of plates $1-8 \mu \mathrm{m}$ thick and a length of 5-15 $\mu \mathrm{m}$. The microstructure and shape of particles of different phases, observed using scanning electron (SEM) and light microscopes, for an ingot of alloy 01390 are shown in Fig. 4. Within the structure there are four forms of particles: crystals of primary silicon in the form of faceted plates with a size of 5-70 mm (arrow $A$ ); eutectic silicon crystals (arrow $B$ ); skeletal dendrites and individual fine $\alpha$-phase plates (arrow $C$ ) with thickness of about $1 \mu \mathrm{m}$ and $20 \mu \mathrm{m}$ long, containing manganese, iron, and silicon; fine equiaxed secondary silicon particles with sizes of $0.2-1.0 \mu \mathrm{m}$.

After ingot deformation as a result of pressing and helical rolling (HR), the average size of silicon crystals did not change in a similar way (Fig. 5) [1]. 

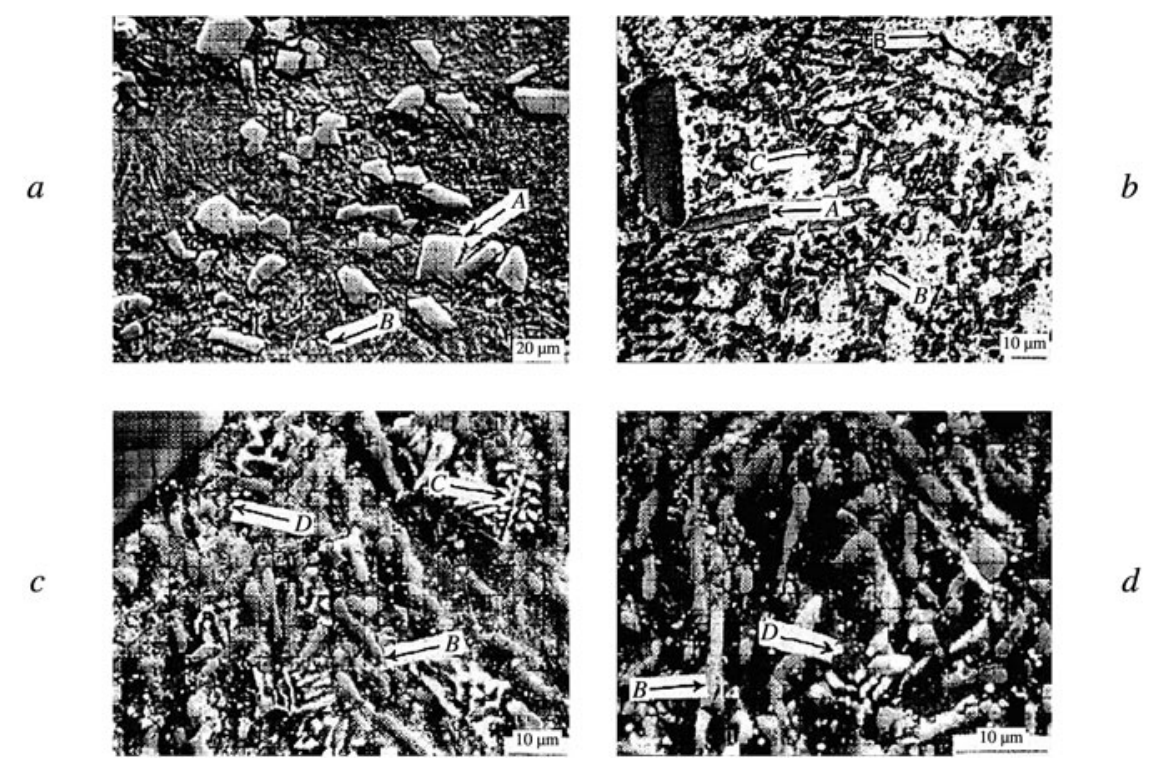

Fig. 4. Microstructure of ingot $112 \mathrm{~mm}$ in diameter: $a, c, d$ ) SEM; $b$ ) light microscopy.

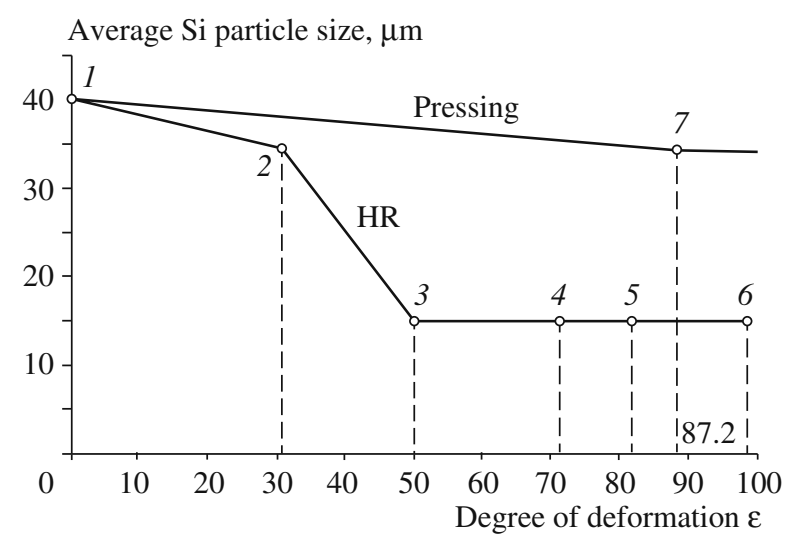

Fig. 5. Dependence of average primary silicon dimensions within structure of ingot and bars of alloy 01390 after HR and pressing on degree of deformation: 1) ingot $112 \mathrm{~mm}$ in diameter; 2) bar $92 \mathrm{~mm}$ in diameter $(\varepsilon=32 \%, \mu=1.5)$; 3) bar $80 \mathrm{~mm}$ in diameter $(\varepsilon=49 \%, \mu=1.96)$; 4) bar $60 \mathrm{~mm}$ in diameter $(\varepsilon=71 \%, \mu=3.5)$; 5) bar $50 \mathrm{~mm}$ in diameter $(\varepsilon=81 \%, \mu=5.0)$; 6$)$ bar $14 \mathrm{~mm}$ in diameter $(\varepsilon=98 \%, \mu=64.0) ; 7)$ bar $40 \mathrm{~mm}$ in diameter $(\varepsilon=87.2 \%, \mu=5.7)$.

For a more complete study on the size of hypereutectic silumin silicon crystals by different forms of forming (pressing and HR), and also the degree of deformation $\varepsilon$, microsections were studied with prior determination in the same field $(0.65 \times 0.65 \mathrm{~mm})$ of silicon crystal dimensions, the number of them in a field of a microsection, and their distribution density: in an original ingot; in bars $92,80,50$, and $14 \mathrm{~mm}$ in diameter prepared by the HR method, compared with bar $40 \mathrm{~mm}$ in diameter prepared by pressing (Table 2). Billets for pressing and HR were cut from a single ingot with the same original maximum silicon crystal size $a_{0} \approx 40 \mu \mathrm{m}$. It is possible to draw a conclusion from data in Fig. 5 and Table 2: with pressing in contrast to HR, even with small degrees of deformation $(\varepsilon=87.2 \%)$, silicon crystal refinement hardly occurs, i.e., the average (minimum possible) size of crystals is $35 \mathrm{~mm}$, and this almost agrees with their dimensions in the original ingots $(40 \mu \mathrm{m})$ with HR this results $(35 \mu \mathrm{m})$ is achieved with significantly smaller degrees of deformation $(\varepsilon=32 \%)$. 
TABLE 2. Effect of Metal Forming Methods and Degree of Deformation on Average Dimensions, Amount, and Density of Silicon Crystals within Alloy 01390 Ingot and Bar Structure

\begin{tabular}{|c|c|c|c|c|c|c|}
\hline $\begin{array}{l}\text { Semifinished } \\
\text { product }\end{array}$ & $\begin{array}{l}\text { Diameter, } \\
\mathrm{mm}\end{array}$ & $\begin{array}{l}\text { Metal forming } \\
\text { method }\end{array}$ & $\begin{array}{l}\text { Degree of } \\
\text { deformation }\end{array}$ & $\begin{array}{l}\text { Average } \mathrm{Si} \text { crystal } \\
\text { size, } \mu \mathrm{m}\end{array}$ & $\begin{array}{l}\text { Amount } n \text { in microsection field } \\
\text { with size } 0.65 \times 0.65 \mathrm{~mm}\end{array}$ & $\begin{array}{l}\text { Density of Si crystals in } \\
\text { microsection per } 1 \mathrm{~mm}^{2}\end{array}$ \\
\hline Ingot & 112 & - & - & 40 & 40 & 94.6 \\
\hline \multirow{5}{*}{ Bar } & 92 & \multirow{4}{*}{ HR } & 32 & 35 & 64 & 151.4 \\
\hline & 80 & & 50 & 15 & 234 & 553.8 \\
\hline & 52 & & 78 & 15 & 234 & 553.8 \\
\hline & 14 & & 98 & 15 & 234 & 553.8 \\
\hline & 40 & Hot pressing & 87.2 & 35 & 64 & 151.4 \\
\hline
\end{tabular}
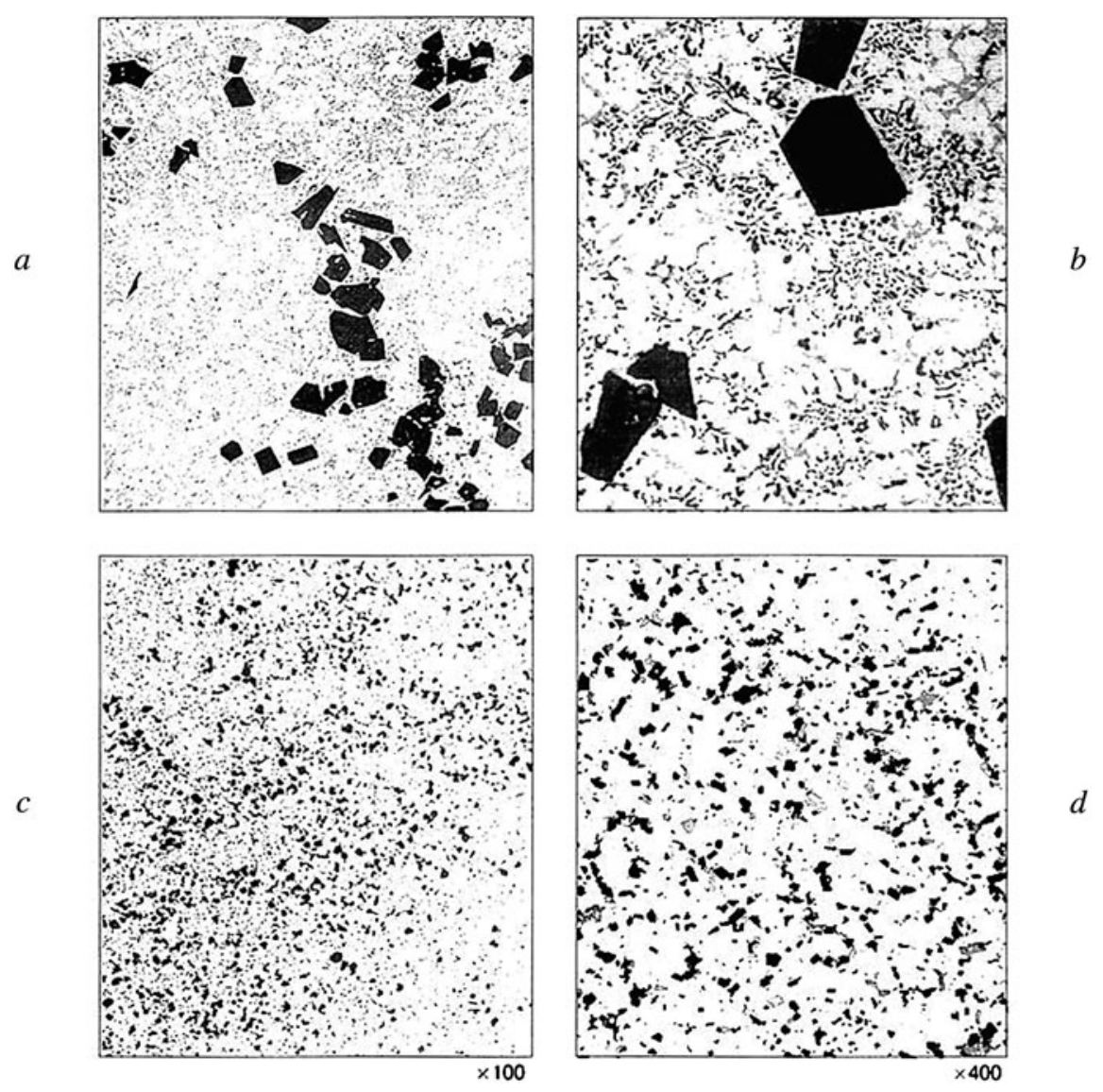

Fig. 6. Typical microstructure of ingots $(a, b)$ and bars rolled from them $(c, d)$ of silumin 01392 [25].

This fact is explained in [2]: the process of pressing is characterized by a classical scheme of all-round compression and with a three-roll HR scheme there are areas of action of both compressive stress and also tensile stress. As a result of the fact that during HR (in contrast to pressing) a billet simultaneously has alternating and rotary movement, the same volume of billet metal is at the deformation site, and it is repeatedly subject to action of stresses of different directions.

The microstructure of rolled product obtained as a result of HR differs qualitatively from that of the original ingots (Fig. 6). 

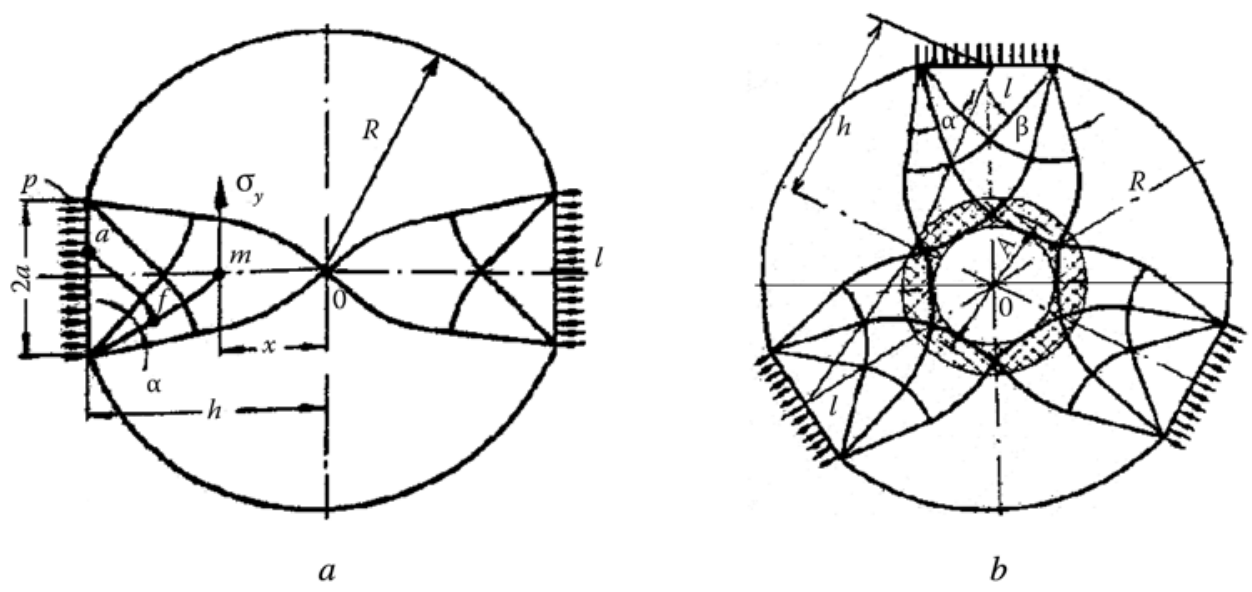

Fig. 7. Network of slip lines: $a$ ) for two-roll and $b$ ) three-roll rolling schemes.

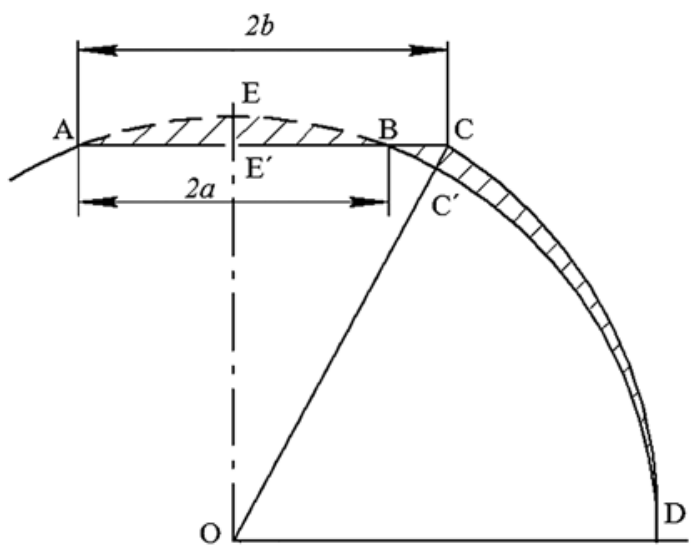

Fig. 8. Metal shape change in contact region.

With HR and a degree of deformation above $50 \%$ (see Fig. 5), the sizes of primary silicon crystals decrease by a factor of three to four and reach $10-15 \mu \mathrm{m}$, and lamellar secondary silicon crystals acquire a globular shape and there is a reduction in order. A further increase in the degree of deformation does not lead to greater silicon crystal refinement and the microstructure as a whole. It is necessary to study additionally the effect on structure of other HR parameters (for example, HR with small deformation rates $\dot{\varepsilon} \approx 0.1 \mathrm{sec}^{-1}$ ).

HR is one of the most complex forming processes. At the same time, the effect of stress-strain state (SSS) of this process on the change in structure and ductility of other metals and alloys has hardly been studied.

Effect of SSS with HR on the change in structure and ductility of metals. In metal forming theory a study of SSS and breakdown of metal with screw rolling remains an important task. There is particular value in results of studying the effect of the alternating nature of deformation on physicomechanical properties and steel and alloy structural state.

It is well known [3] that with greater ductility alternating deformation as a result of Bauschinger, Masing, and cyclic strengthening effects considerably reduces the intensity of metal strengthening. These effects are structure sensitive, and the average normal stress and total degree of alternating strain, caused by external effect on a deformable body, as results of tests have shown [26], does not have a marked effect on strengthening. At the same time, metal ductility with alternating deformation $\left(\Lambda_{p n}\right)$ anomalously increases with an increase in amplitude $\Lambda_{i}: \Lambda_{p n}=\Lambda_{p 0}\left(\Lambda_{p 0} / \Lambda_{i}\right)^{a-1}$, where $\Lambda_{p 0}$ is the ductility with uniform deformation, depending on stressed state indices $\sigma / T$ and Lode-Nadai index $\mu_{\sigma} ; a \approx 2$ is an empirical coefficient. 

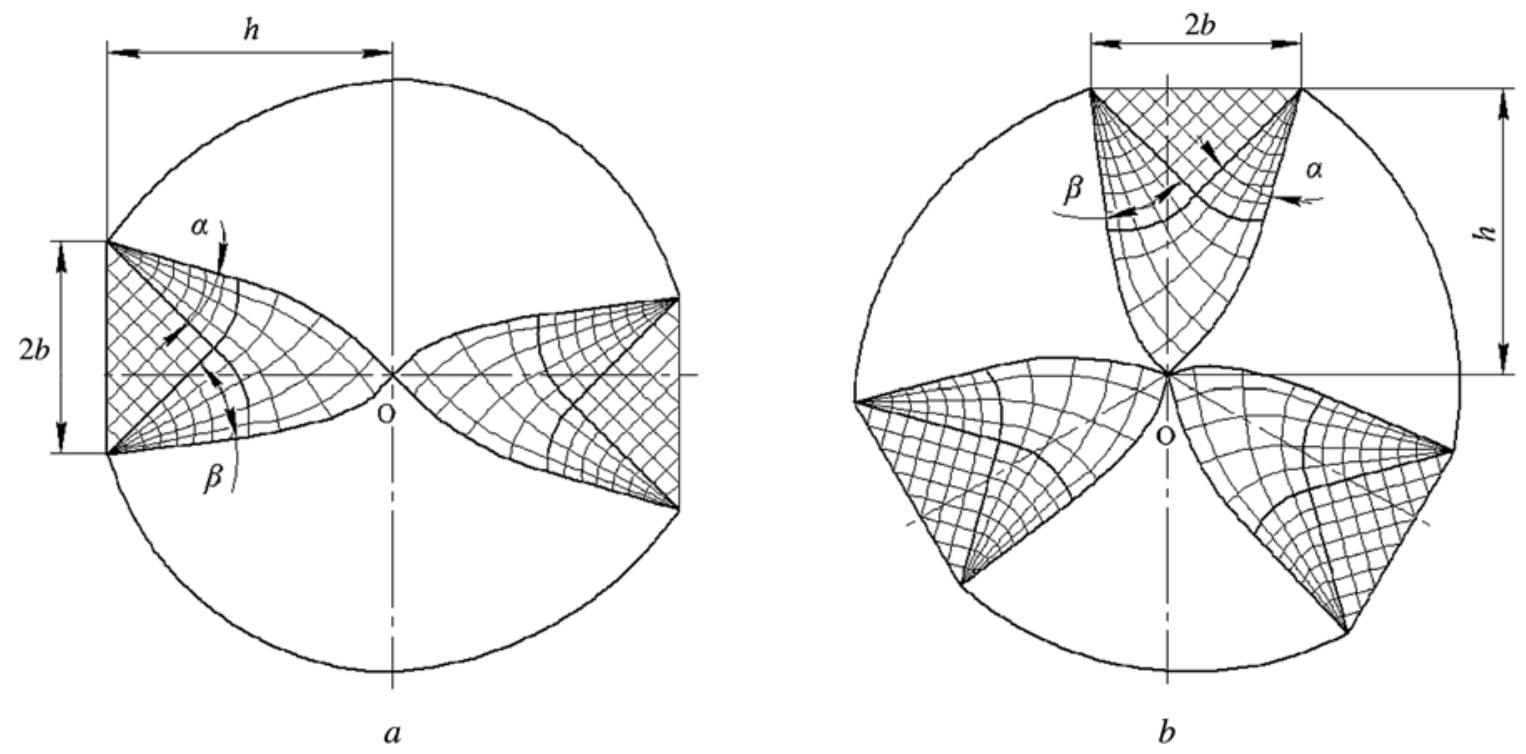

Fig. 9. Network of slip lines taking account of metal tangential flow for two-roll $(a)$ and three-roll $(b)$ rolling schemes.

In studying the effect of HR reduction for steel $32 \mathrm{KhG}$ in a three-roll mill as a result of the alternating nature of deformation compared with longitudinal rolling there is a reduction in austenitic grain size by a factor of 5-6 [4]. Due to work in [5-8] it is possible to evaluate the stressed state indices in the cross section of a rolled billet. The index $\sigma / T$ has the smallest value in the area in contact with rolls, and the greatest value, in the axial area. A network of slip lines is shown in Fig. 7 for two-roll $(a)$ and three-roll $(b)$ rolling schemes. It is assumed that the metal contact boundary with a tool is rectilinear, there are no friction stresses, and normal stresses are uniformly distributed over the contact surface.

The field of slip lines adjacent to tool consists of an isosceles triangle, two central fields, and one $(a)$ or two $(b)$ curvilinear rectangles. Angles $\alpha$ and $\beta$ are determined from symmetry conditions for the deformation site, and average normal stress in a triangle of region $\sigma$ is determined from the statistical boundary conditions in the form of an equilibrium equation $\int_{0}^{h} \sigma_{y y} d x=0$. It is easy to believe that the lower boundary of application of the slip line field (see Fig. $7 a$ ) is the ratio $h / a=1$, and the upper boundary is $h / a=8.5$. In the first case, in a triangular region and simultaneously point $0, \sigma / T=-1$, and in the second case in this region $\sigma / T=-4.14$; deformation is localized at the contact with a tool, and does not penetrate up to the axis of symmetry. At point 0 , the value of index $\sigma / T$ depends on the ratio $h / a$.

With transverse rolling, if partial reduction $\Delta R / R=0.02$, then as experiments show, deformation penetrates into the axis of the billet area, within with $\sigma / T \approx 1.0$, i.e., tensile stresses predominate, and metal ductility is much less than in the contact area. In the case of rolling in three rolls (see Fig. 7b) by means of a network of slip lines in a billet it is possible to reveal a circular area within which metal is loosened more rapidly and macrofailure may occur. The axial area in the form of a cylinder is a region of uniform tensile deformation, within which there are stressed state indices: $\sigma / T=0.58$, but $\mu_{\sigma}=-1$. In the rest of the area, there is plastic deformation with fulfilment of the plane strain condition $\mu_{\sigma}=0$.

The deformation site schemes in question (see Fig. 7) do not consider an important feature of billet shape change, connected with the developed tangential metal flow (Fig. 8). The volume of metal from segment AEB with stretching coefficient $\lambda=1$ shifts in a tangential direction into region $\mathrm{BCD}$. Ahead of a roll laps form during rolling and there is an increase in contact surface width to the value $\Delta R=\mathrm{EE}^{\prime}+\mathrm{CC}^{\prime}$. It is seen that single reduction $\Delta R$, determined taking account of a lap, significantly exceeds singe reduction without taking account of tangential deformation. 
A network of slip lines with consideration of developed tangential flow is shown in Fig. $9 a$ for two rolling schemes. From consideration of deformation site geometry it is seen in Fig. $9 b$ that an increase in partial reduction $\Delta R$ leads to a reduction in angles $\alpha$ and $\beta$, and also radius of the axial zone of uniform tensile deformation in the form of a cylinder. In Fig. $9 b$, region $A$ (see Fig. 7) is absent and $R_{A}=0$, i.e., this is the most favorable case for achieving uniform deformation in a billet cross section and a fine structure.

A distinguishing feature of screw rolling is the alternating nature. Deformation amplitude equals numerically the degree of shear deformation $\Lambda_{i}$ in the $i$ th stage. It is easy to show that any billet particle with a two-roll rolling scheme undergoes two alternating deformation cycles, and with a three-roll scheme it undergoes three cycles, each of which consists of two stages. Kolmogorov, using a solution of a variation problem, calculated the degree of shear deformation in a billet axial zone and obtained a relationship $\Lambda(\Delta R / R)$ [8]. Using a slip line method, the value of alternating deformation amplitude may

be considered to equal approximately $\Lambda_{i}=\left|\Delta v_{\tau} / v_{n}\right|$, where $\Delta v_{\tau}$ is the jump in tangential component, and $v_{n}$ is the normal velocity vector component in a slip line. Assuming that the degree of shear deformation does not depend on radial coordinate, we obtain $\Lambda_{i}=2 \ln [R /(R-\Delta R)]$. Thus, a material particle with a two-roll scheme for one billet rotation undergoes four deformation stages with degree $\Lambda_{i}=2 \ln [R /(R-\Delta R)]$. A particle, completing alternating rotation with respect to its own stress tensor vector, coinciding with billet axis, experiences two alternating deformation cycles. With a three-roll scheme, a particle experiences three cycles, or six stages of alternating deformation for one billet rotation, and deformation amplitude $\Lambda_{i}=2 \ln [R /(R-\Delta R)]$.

Currently there is no published proof of the effect of alternating deformation on steel and alloy granular structure fineness and phase composition. However, results of structure formation with screw rolling, presented in [9], make it possible to propose this hypothesis.

Conclusion. Favorable results for fundamental refinement of structural components, an increase in ductility of cast hypereutectic silumins with a high silicon content (above 17-20\%), some grades of steel, and also test high-strength cast iron [9], make it possible to consider HR (three-roll scheme) as the most effective of all metal forming methods for improving the mechanical properties of metals that are difficult to deform and other alloy compositions. The stress-strain state of billets, given HR, requires more profound study.

\section{REFERENCES}

1. E. I. Panov, Plastic Deformation of Cast Hypereutectic Silumin Alloys with a High Silicon Content [in Russian], Metallurgizdat, Moscow (2012).

2. E. I. Panov, "Main factors affecting the mechanism of structure formation and increasing hypereutectic silumin ductility properties with three-roll helical rolling," Metallurg, No. 4, 69-75 (2006).

3. A. A. Bogatov, Metal Mechanical Properties and Failure Models [in Russian], UGTU-UPI, Ekaterinburg (2002).

4. D. V. Ovchinnikov, A. A. Bogatov, and M. V. Erpalov, "Development and introduction of manufacturing technology for compressor pump pipes from a continuously-cast billet," Chern. Met., March, 18-21 (2012).

5. A. I. Tselikov, V. M. Lugovskii, and E. M. Tret'yakov, Vestn. Mashinostr., No. 7, 49 (1961).

6. V. C. Smirnov, Transverse Rolling [in Russian], Mashgiz, Moscow (1949).

7. A. D. Tomlenov, Metal Forming Mechanics [in Russian], Mashgiz, Moscow (1963).

8. V. A. Kolmogorov, Stresses, Strains, Failure [in Russian], Metallurgiya, Moscow (1970).

9. B. A. Romantsev and A. V. Lisovskii, "Study of the possibility of thermoplastic processing of high-strength cast irons," Continuous Forming: Proc. All-Russ. Sci.-Tech. Conf. Devoted to the 100th Anniversary of Academician A. I. Tselikov, Moscow (2004), pp. 38-42. 